\title{
OS ANIMAIS DOS CAMPOS GERAIS (PR): IMPACTOS AMBIENTAIS NOTICIADOS PELA IMPRENSA REGIONAL
}

\author{
THE ANIMALS OF CAMPOS GERAIS (PR): ENVIRONMENTAL \\ IMPACTS PUBLISHED BY THE LOCAL PRESS
}

\author{
Olavo Martins Ayres \\ Universidade Estadual de Ponta Grossa - UEPG, Departamento de Métodos e Técnicas de \\ Ensino, Campus Central, Ponta Grossa, PR; (42) 3220-3374; Programa de Pós-Graduação em \\ Ecologia e Recursos Naturais, UFSCar, SP; e-mail: oayres@uol.com.br \\ Recebido para publicação em 01/03/2006 \\ Aceito para publicação em 24/05/2006
}

\section{RESUMO}

Esse trabalho relaciona-se a estudos sobre a fauna dos Campos Gerais do Paraná, no caso particular, a partir de informações indiciais publicadas em jornais de circulação regional, em que, com destaque, animais vertebrados são direta e/ ou indiretamente afetados por impactos ambientais. Com base nesses veículos, os objetivos da presente pesquisa foram: contribuir na documentação das informações sobre as espécies de animais ocorrentes nos Campos Gerais do Paraná; detectar impactos ambientais relacionados, as espécies e grupos mais afetados, e pontos de incidência desses agravos. Os dados foram coletados em 05 jornais no período de 1997 a 2000. Foram selecionadas 34 matérias jornalísticas, e identificadas no mínimo 29 espécies, sendo 07 mamíferos, 13 aves, 01 réptil, e 08 peixes; e fósseis do Devoniano. O maior número de notícias está relacionada ao tráfico de animais, estando confirmada rota pela região. Fatores como poluição por agrotóxicos e por resíduos industriais em bacias hidrográficas estendem os agravos a outros componentes do ecossistema, incluindo o homem, e a própria paisagem dos Campos Gerais. O levantamento de informações sob esse viés pode ser útil e instrutivo, a medida em que, como metodologia acessória, se some à pesquisa ecológica e etnoecológica básica. Presta-se também, como recurso didático auxiliar, subsidiando programas de Ensino Médio e Fundamental na produção de materiais didáticos para Biologia e Ciências, e, sob a ótica da inter e transdisciplinaridade, para outras disciplinas; e também na Educação Ambiental. Isto, quando voltados à realidade local/regional, com base em fatos do cotidiano, e à Conservação Ambiental.

Palavras-chave: fauna dos Campos Gerais, impactos ambientais, materiais didáticos regionais, notícias de jornais 


\begin{abstract}
This work is related to studies about the fauna of Campos Gerais in Paraná, particularly, from evident information published in newspapers of local distribution, in which, vertebrate animals are directly and/or indirectly affected by environmental impacts. Based on this media, the aims of this research were to contribute to the documentation of information about species of animals which are from Campos Gerais in Paraná; to detect environmental impacts related to the species and groups most affected, and episodes were damage happens. The data was collected from 5 newspaper in the period from 1997 to 2001.34 newspaper articles were selected, and a minimum of 29 species were identified: 07 mammals, 13 birds, 01 reptile, and 08 fish, and fossils of the Devonian. Most of the news are related to the traffic of animals, with the route through this region being confirmed. Factors such as polution by poisonous chemicals and by industrial waste in hydrographic bay spread the damage to other components of the ecosystem, including the man, and the landscape of Campos Gerais itself. This survey, from this point of view, can be very useful and educative as a supplementary methodology for basic ecological and ethnoecological research. It can also be useful as an additional didatic tool, supporting programmes of the high school and primary school in the production of didatic materials to Biology and Science, and, from the point of view of the inter and transdisciplinarity, to other school subjects; and also to Environmental Education. This, when related to the local/regional reality, based on daily facts, and to the Environmental Conservation.
\end{abstract}

Key words: fauna of Campos Gerais, environmental impacts, regional didatic materials, newspaper articles

\section{Introdução}

A ciência está no cotidiano, e a ele deve retornar. A imprensa registra os acontecimentos do cotidiano no instantâneo, quase aleatoriamente, em função da ocorrência do que possa ser considerado como notícia. Os fatos da ciência por sua vez são sistematizados e analisados ao longo de um processo. Embora poucos tenham abordado sobre a utilização de notícias de jornais como metodologia acessória na pesquisa e/ou como recurso didático (entre eles, John, 1996; Oliveira, 1992; Severino, 1996, 1995), mesmo que de forma pontual, matérias jornalísticas são utilizadas em teses, dissertações e trabalhos técnicos, documentando os aspectos abordados.

A descoberta do patrimônio paleontológico de Lagoa Santa, em Minas Gerais, por Lund é atribuída a uma fotografia impressa em obscuro jornal. $\mathrm{Na}$ fotografia de imprensa, percebe-se a coexistência de duas mensagens: uma denotada, que é o próprio analogon, que define a fotografia para o senso comum; e uma mensagem suplementar, conotada, onde "o significante é um tratamento da imagem sob a ação do criador e cujo significado, é remetido à cultura de quem recebe a mensagem" (Barthes, 1978).

Para a pesquisa zoológica/etnozoológica e ecológica/etnoecológica esse rastreamento de fragmentos de informações em matérias jornalísticas pode tornar-se importante, à medida em que o pesquisador amplia sua base de informações sobre as espécies e aspectos do ambiente, e tenta traduzir as diversas percepções e formas de documentação do espaço natural e seus componentes, com o rigor do método científico. 
A fauna brasileira está entre as mais ricas em diversidade do planeta, mas, também é das mais ameaçadas e menos conhecidas. Essa insuficiência de informações sobre a zoologia e ecologia das espécies ocorrentes foi ressaltada à nível nacional, e para o estado do Paraná, e na microregião dos Campos Gerais, em relação aos mamíferos (p. ex. Borges, 1989; Silva, 1984), as aves (Sherer-Neto; Straube, 1995; Straube, 1995), e os peixes (Bennemann; Shibata; Garavello, 2000; Severi; Cordeiro, 1994). Apesar do sensível acréscimo de pesquisas e (re)publicações nos últimos anos, a população urbana brasileira só tem, em geral, acesso às informações que se encontram nos livros de zoologia, fascículos, e filmes para televisão, ricamente ilustrados com espécies animais de outras partes do mundo (Silva, 1984).

Considerando a Educação como elemento fundamental para a solução da questão ambiental, os Parâmetros Curriculares Nacionais (PCN) do Ensino Médio do Ministério da Educação, por sua vez, intencionam "dar significado ao conhecimento escolar mediante a contextualização, e evitar a compartimentalização, mediante a interdisciplinaridade. E que "os alunos devem ser capacitados para julgar as intervenções do homem no meio ambiente e o aproveitamento de recursos naturais" (BRASIL). Entretanto, os livros didáticos brasileiros ou de divulgação popular que tratam dos grupos de vertebrados (apenas para permanecer nesse caso) são, grosso modo, traduções ou adaptações de obras estrangeiras. Ademais, ainda existe uma lacuna muito grande também em relação aos materiais pedagógicos voltados à Educação Ambiental, particularmente no Brasil; fator que tem sido apontado como um dos mais difíceis a serem superados (John, 1996; Oliveira, 1992; Sato, 1995).

Nesse sentido, a triste realidade do ambiente agredido e devastado no País, e no caso particular, dos Campos Gerais do Paraná, per si, justifica o recolhimento e a organização de materiais sobre o assunto, assegurando a manutenção da memória histórica da região. Para os professores do Ensino Fundamental e Médio, um dos modos de transformação desta realidade é no trabalho em sala de aula de capacitação e conscientização dos alunos a partir da análise dos registros documentais dos fatos da atualidade, e a constituição de hemerotecas em escolas pode ser um importante instrumento no âmbito de um processo de ensino investigativo (exemplo concreto em Oliveira, 1992).

A carência de técnicos e profissionais para investigar (e proteger) as espécies animais, e os constantes agravos a que estão submetidas nos ambientes em que vivem, assim como, as pesquisas raras e descontínuas, a falta de financiamento à pesquisas, $\mathrm{o}$ imediatismo das administrações públicas, e uma lacuna dos livros didáticos que praticamente não tratam da região apesar da sua importância ambiental, histórica e cultural, estimulam proposições como essa.

Os objetivos principais que nortearam esse trabalho foram, a partir de notícias de jornais: levantar informações sobre os animais ocorrentes na região dos Campos Gerais do Paraná; identificar impactos ambientais relacionados, as espécies e grupos animais mais afetados, e os pontos de incidência desses agravos. Isto, visando contribuir na organização de informações básicas que subsidiem ações de manejo e planejamento ambiental, assim como programas de ensino, que estimulem a produção de materiais didáticos regionais.

\section{Material e métodos}

Foram realizadas pesquisas em jornais da região, a busca de informações sobre a fauna ocorrente nos Campos Gerais/Alto e Médio Tibagi (Estado do Paraná) e os impactos ambientais relacionados. Os jornais pesquisados foram: Diário da Manhã (DM), Diário dos Campos (DC), e Jornal da Manhã (JM), do município de Ponta Grossa, e Página Um (PU) e O Estado do Paraná (OEPR), respectivamente de Castro e Curitiba. O período de coleta de dados estendeu-se de agosto de 1997 a outubro de 2000, com acompanhamento diário. Uma matéria, de outubro de 2001, foi tabulada conjuntamente para confirmação de hipóteses ao longo do tempo.

Os locais das ocorrências apontadas localizamse nos municípios de Piraí do Sul, Castro, Tibagi, Carambeí, Ponta Grossa, Ipiranga e Porto Amazonas, compreendidos entre os paralelos $24^{\circ} 15^{\prime} \mathrm{S}$ e $25^{\circ} 40^{\prime}$ $\mathrm{S}$, e meridianos $49^{\circ} 30^{\prime} \mathrm{W}$ e $50^{\circ} 45^{\prime} \mathrm{W}$.

A nomenclatura das espécies de animais citados, e em alguns casos fotografados, nas notícias sele- 
cionadas foi feita com base na literatura pertinente, a saber, para os mamíferos em geral (Carvalho,1983; Silva, 1984), para os felinos (Oliveira, 1994), para as aves (Sherer-Neto; Straube, 1995; Sick, 1997), e os peixes (Bennemann; Shibata; Garavello, 2000; Severi; Cordeiro, 1994). Fóssil documentado em matéria jornalística, foi identificado na obra de J. C. Mendes.

\section{Resultados e discussão}

Em relação à fauna ocorrente na região dos Campos Gerais, a pesquisa a partir de notícias jornalísticas revelou que, mesmo as matérias não tendo sido escritas ou fotografadas por profissionais ou especialistas em questões ambientais, em muitos momentos, documentam e registram os fatos a serem investigados (Tabela 1). As reportagens em que os animais foram citados, mostrados ou aludidos, em geral são manchetes de primeira página, entretanto ao serem remetidas, não têm um lugar definido, podendo ser encontradas em editorias como Cotidiano, Geral, Cidades, e mais comumente Segurança ou Polícia, o que coincide com outro trabalho realizado a esse respeito (John, 1996). As noticias selecionadas, tabuladas cronologicamente, constam em Apêndice.

As matérias jornalísticas que documentam a fauna ocorrente na região, via de regra reportam ações conjuntas da Polícia Florestal e IBAMA. Nestas, explicita-se que "região dos Campos Gerais apresenta maior índice do Paraná de infrações contra meio ambiente" (DM 25/04/98), e que o efetivo de apenas 24 guardas-florestais, quase sem viaturas ou equipamentos, para cobrir 1.300 hectares abrangendo 11 municípios, deixa-os apreensivos diante da superioridade do "poder de fogo" dos caçadores, da pesca predatória em maior número em Ponta Grossa no reservatório de Alagados e no Rio Tibagi, e outros delitos. Esse tipo de relato é encontrado em diversas matérias, reiterando as dificuldades dos órgãos competentes em coibir as agressões ao meio, acentuadas pela burocracia que faz com que os processos se arrastem durante anos. 
Tabela 1 - Animais dos Campos Gerais (Paraná) noticiados pela imprensa regional e impactos ambientais relacionados

\begin{tabular}{|c|c|c|}
\hline Animal(is) & Causa/Município & Situação \\
\hline Lobo-guará & $\begin{array}{l}\text { Procura de alimento e água (?)/ Vila Ana } \\
\text { Rita, Ponta Grossa }\end{array}$ & $\begin{array}{l}\text { Animal capturado em área urbana pela Polícia } \\
\text { Florestal, e solto no P.E. de Vila Velha }\end{array}$ \\
\hline Lontra & Caça ilegal/Castro & Pele (1) apreendida \\
\hline Lontra & $\begin{array}{l}\text { Crianças encontraram um filhote/ Rio } \\
\text { Verde, Ponta Grossa }\end{array}$ & $\begin{array}{l}\text { O filhote de lontra foi levado ao Passeio Público } \\
\text { em Curitiba }\end{array}$ \\
\hline Onça-parda & $\begin{array}{l}\text { Incêndio no P.E. de Vila Velha (?) } \\
\text { /Ponta Grossa }\end{array}$ & $\begin{array}{l}\text { Captura do animal em área urbana para posterior } \\
\text { soltura no P.E. de Vila Velha }\end{array}$ \\
\hline Gato-do-mato & $\begin{array}{l}\text { Moradores encontraram animal/ } \\
\text { Catanduva de Fora, Castro }\end{array}$ & $\begin{array}{l}\text { Animal encaminhado para Ponta Grossa, e em } \\
\text { seguida para PUC-Curitiba }\end{array}$ \\
\hline Jaguatirica & $\begin{array}{l}\text { Caça ilegal para comércio/distrito de } \\
\text { Santa Cruz, Ponta Grossa }\end{array}$ & $\begin{array}{l}\text { Pele (1) apreendida, juntamente com pacas e } \\
\text { aves }\end{array}$ \\
\hline Veado & Caça ilegal/Castro & Peles (2) apreendidas \\
\hline Veado & Caça e comércio ilegal de animais/ & $\begin{array}{l}\text { Pele (1), e patas apreendidas, juntamente com } \\
\text { aves e armas }\end{array}$ \\
\hline Paca (7 espécimes) & $\begin{array}{l}\text { Apreensão de } 07 \text { pacas, em } \\
\text { cativeiro/distrito de Santa Cruz, Ponta } \\
\text { Grossa }\end{array}$ & $\begin{array}{l}\text { Animais com ferimentos e estressados; foram } \\
\text { soltos no P.E. de Vila Velha. }\end{array}$ \\
\hline $\begin{array}{l}\text { Pássaros (48): Canários-da-terra (22), } \\
\text { caboclinhos (9), azulões (5), sabiás (3), } \\
\text { curiós (2), coleirinhas (2), chupins (2), } \\
\text { pintassilgos (2), tiriva-de-testa (1) }\end{array}$ & Aves em cativeiro/Ponta Grossa & Apreensão, quarentena (em Curitiba) \\
\hline $\begin{array}{l}\text { Pássaros (26): canários-da-terra (12), } \\
\text { coleirinhas (14) }\end{array}$ & Apreensão/região de Ponta Grossa & $\begin{array}{l}\text { Animais provavelmente libertados; a nota não } \\
\text { informa }\end{array}$ \\
\hline $\begin{array}{l}\text { Pássaros (100): canários-da-terra (96), } \\
\text { azulão (1), tico-tico-rei (1), pintassilgo } \\
(1), \text { curió (1) }\end{array}$ & $\begin{array}{l}\text { Apreensão de aves em cativeiro, rota de } \\
\text { tráfico de animais/área central, Ipiranga }\end{array}$ & $\begin{array}{l}\text { Animais soltos no P.E. de Vila Velha, } 17 \text { deles } \\
\text { estavam mortos; "o curió será solto apenas no } \\
\text { Parque Iguaçu, em Curitiba" }\end{array}$ \\
\hline $\begin{array}{l}\text { Pássaros (370): caboclinhos (18), } \\
\text { pintassilgos (14), canários-da-terra } \\
(338)\end{array}$ & $\begin{array}{l}\text { Apreensão de aves, tráfico de animais / } \\
\text { Ponta Grossa }\end{array}$ & $\begin{array}{l}\text { Cinco (5) pássaros estavam mortos, e soltura dos } \\
\text { demais no Parque Estadual de Vila Velha }\end{array}$ \\
\hline $\begin{array}{l}\text { "Pássaros silvestres" (8): espécies não } \\
\text { citadas }\end{array}$ & $\begin{array}{l}\text { Apreensão de aves, tráfico de animais / } \\
\text { Ponta Grossa }\end{array}$ & $\begin{array}{l}\text { Os animais, debilitados, foram soltos no P.E. de } \\
\text { Vila Velha }\end{array}$ \\
\hline Curiós, arapongas, pássaros-pretos (n) & $\begin{array}{l}\text { Captura para comércio por pessoas } \\
\text { estranhas ao lugar/Canyon do Guartelá, } \\
\text { Tibagi }\end{array}$ & $\begin{array}{l}\text { Depoimentos históricos de moradores locais } \\
\text { reportados }\end{array}$ \\
\hline $\begin{array}{l}\text { Pássaros (41): canários-da-terra (n), } \\
\text { pintassilgos (n), sabiás (n) }\end{array}$ & $\begin{array}{l}\text { Caça e comércio de animais } \\
\text { silvestres/Porto Amazonas }\end{array}$ & $\begin{array}{l}\text { Animais provavelmente libertados; a notícia não } \\
\text { informa }\end{array}$ \\
\hline Pássaros (10): espécies não citadas & $\begin{array}{l}\text { Apreensão de pássaros em cativeiro/ } \\
\text { local não citado, região de Ponta Grossa }\end{array}$ & $\begin{array}{l}\text { Animais provavelmente libertados; a notícia } \\
\text { também não informa a respeito }\end{array}$ \\
\hline Lagarto-de-papo-amarelo & $\begin{array}{l}\text { Animal apedrejado, iria ser usado para } \\
\text { alimentação/Ponta Grossa }\end{array}$ & Animal morto apreendido (?) \\
\hline $\begin{array}{l}\text { Lambaris, bagres, cascudos, tilápias, } \\
\text { traíras, carás, carpas (centenas) }\end{array}$ & $\begin{array}{l}\text { Poluição por agrotóxicos rios Piraí e } \\
\text { Butiá/Piraí do Sul }\end{array}$ & $\begin{array}{l}\text { Morte de centenas de peixes e outras espécies, } \\
\text { extensão } 20 \mathrm{~km}(?)\end{array}$ \\
\hline Peixes (centenas) & Poluição no rio Pitangui/Ponta Grossa & Morte de centenas de peixes de várias espécies \\
\hline Peixes $(66 \mathrm{~kg})$ & Pesca ilegal na piracema/Castro & Apreensão \\
\hline $\begin{array}{l}\text { Peixes ("não há como contabilizar o } \\
\text { número de peixes mortos") }\end{array}$ & $\begin{array}{l}\text { Descarrilamento de trem, } 13 \text { vagões. } \\
\text { Vazamento estimado } 120 \text { a } 200 \text { mil litros } \\
\text { de etanol, } 60 \text { mil foram queimados; } \\
\text { chamas se alastram } 1 \mathrm{~km} \text { no curso do } \\
\text { arroio/ Espalha Brasas zona rural, Piraí } \\
\text { do Sul }\end{array}$ & $\begin{array}{l}\text { Água imprópria. O IAP instruiu a população a } \\
\text { não consumir os peixes mortos em função do } \\
\text { vazamento de etanol. Também ocorreu queima } \\
\text { de } 1 \text { hectare de vegetação, em área de } \\
\text { preservação permanente. Arroio contaminado } \\
\text { corre para o Rio Piraí Mirim que deságua no Rio } \\
\text { Iapó }\end{array}$ \\
\hline $\begin{array}{l}\text { Peixes (centenas mortos) } 11 \text { espécies } \\
\text { ocorrentes (nominado apenas o } \\
\text { lambari) }\end{array}$ & $\begin{array}{l}\text { Laudo atestou falta de oxigênio na } \\
\text { água/Furna 1, P.E. Vila Velha, Ponta } \\
\text { Grossa }\end{array}$ & $\begin{array}{l}\text { Centenas de peixes mortos, e uma andorinha. } \\
\text { Furna pode abrigar espécie exclusiva de lambari. } \\
\text { Relação andorinhas/peixes pode ser adaptativa, } \\
\text { não impactante }\end{array}$ \\
\hline "Fósseis" da Era Devoniana & $\begin{array}{l}\text { Empresa transforma fósseis em pedra } \\
\text { brita/Bacia do Arroio Olarias, zona } \\
\text { urbana Ponta Grossa }\end{array}$ & $\begin{array}{l}\text { Rochas salvas da compactação estão guardadas } \\
\text { para estudos em laboratórios e posterior envio a } \\
\text { museus }\end{array}$ \\
\hline
\end{tabular}

Fontes: Jornal da Manhã, Diário da Manhã e Diário dos Campos (Ponta Grossa), Página Um (Castro), O Estado do Paraná (Curitiba). 
Dos lamentáveis exemplos, um extremamente significativo, na página Cotidiano a notícia "Empresa transforma fósseis em pedra brita no município" (JM $25 / 05 / 1999)$, e ilustrada com foto de fósseis em arenito (Tabela 2). Com certeza isso ocorre a tempos, mas, trata-se de um caso de irresponsabilidade com o patrimônio ambiental e científico internacional.

Entre os mamíferos registrados, 06 (seis) deles estão incluídos na Lista Oficial Brasileira de Espécies Ameaçadas (Webmaster IBAMA), sendo endemismos neotropicais primários e secundários (Gilmore,
1986) (Tabela 2). Na Lista Vermelha de Animais Ameaçados de Extinção no Estado do Paraná, o curió (Orizoborus angolensis) é acrescido a estes (Margarido, 1995; Straube, 1995). No total, vinte e nove espécies de animais vertebrados foram citadas pelo nome popular, subsidiando suas identificações, a saber: 07 mamíferos, 13 aves, 01 réptil, e 08 peixes (Tabela 3). Pesquisas etnoecológicas e ecológicas no campo, e pesquisas bibliográficas e museológicas, corroboram, e se permeiam aos dados obtidos (Ayres, 2002).

Tabela 2 - Mamíferos ameaçados de extinção e fósseis da região dos Campos Gerais (Paraná) detectados com base em notícias de jornais

\begin{tabular}{l|c|c}
\hline \multicolumn{1}{c|}{$\begin{array}{c}\text { Nome Popular/ } \\
\text { Nome Científico }\end{array}$} & Categoria & Endemismo neotropical \\
\hline $\begin{array}{l}\text { Lobo-guará } \\
\text { Chrysocyon brachyurus (Illiger, 1815) }\end{array}$ & Em perigo & Secundário \\
\hline $\begin{array}{l}\text { Lontra } \\
\text { Lutra longicaudis (Olfers, 1818) }\end{array}$ & Vulnerável & Secundário \\
\hline $\begin{array}{l}\text { Suçuarana, onça-parda } \\
\text { Puma concolor (Nelson \& Goldman, 1929) }\end{array}$ & Vulnerável & Secundário \\
\hline $\begin{array}{l}\text { Jaguatirica } \\
\text { Leopardus pardalis (Cuvier, 1820) }\end{array}$ & Vulnerável \\
\hline $\begin{array}{l}\text { Gato-do-mato-maracajá } \\
\text { Leopardus wiedii (Schinz, 1821) }\end{array}$ & Secundário \\
\hline $\begin{array}{l}\text { Paca } \\
\text { Agouti paca (Linnaeus 1766) }\end{array}$ & Vulnerável & Primário, exclusivo \\
\hline
\end{tabular}

Fósseis - paleocomunidade devoniana bentônica marinha de briozoários

Australospirifer iheringi - em jazigo fossilífero do tipo monoespecífico - Arenito Tibaji, Formação Ponta Grossa (Bacia do Paraná).

O guará (Chrysocyon brachyurus) e a onçaparda (Puma concolor) estão entre os maiores mamíferos exemplificados, e dependem de uma grande área de vida (home range) para poder sobreviver (Borges, 1989; Oliveira, 1994; Silva, 1984). Fatores como desmatamentos, expansão desordenada das cidades, queimadas, aumento de áreas agriculturáveis e exploração ecoturística, devem estar entre as razões para que os animais fossem encontrados longe de seus habitats naturais. A fragmentação de habitats terrestres nos Campos Gerais do Paraná assim como a poluição das águas, aumentam a vulnerabilidade ecológica dos mesmos à extinção das espécies. Os felinos, em particular, são caçados na região sob a alegação que atacam as criações. As peles de cervídeos apreendidas, que foram noticiadas, devem ser de Mazama americana (o veado-pardo) tradicionalmente usadas na região como aperos de montaria, e as patas, como cabides. Em toda sua área de ocorrência, a lontra é caçada pelo valor de sua pele, e a paca, pelo fato de sua carne ser muito apreciada (Ayres, 2002). Esta última, no caso específico da matéria publicada, deve estar relacionada ao tráfico de animais, pelo fato de sete espécimes terem sido capturados em única apreensão, e as aves, pele, e armamentos apreendidos conjuntamente. $\mathrm{O}$ aparato dos caçadores constitui um outro aspecto que pode ser investigado com base nesses veículos.

Notícias relacionadas ao tráfico de animais tiveram destaque, porém, a dificuldade para toda pesquisa com base em jornais é a falta de acompanhamento, pois, quando o fato deixa de ser notícia, ele sai da pauta. Ao pesquisador interessado, cabe entrar em contato com os órgãos envolvidos à busca de informações específicas; Polícia Florestal, IBAMA, e 
no caso do Paraná, o IAP (Instituto Ambiental do Paraná). Na amostragem realizada, o canário-da-terra (Sicalis flaveola), desponta como a espécie mais capturada. Entre as apreensões realizadas pela Polícia Florestal, que foram noticiadas, nota-se a desproporcionalidade da ocorrência dessa espécie em relação às demais nos totais apreendidos, por exemplo, 12/ 26, 96/100, 338/370 (como mostra a Tabela 3). Isso deve-se também ao fato de Sicalis flaveola ser treinado em rinhas, chegando a custar " 2 mil reais" (DC 24/11/2002); as rinhas de briga de galo (Gallus domesticus) também são comuns na região.

A extinção da Delegacia Regional do IBAMA em Ponta Grossa, que ocorreu no ano de 2001, não contribui em nada para a resolução dos problemas detectados, e pode estimular o agravamento destes. Acreditamos que o presente trabalho é um dos inúmeros argumentos que apontam a necessidade da re-implantação dessa Delegacia Regional. Também para que, em Ponta Grossa, seja implantado com urgência um Centro de Triagem de Animais, e de modo ideal (diante das circunstâncias), os animais fossem soltos o mais próximo possível de onde foram encontrados ao invés de enviados para Curitiba ou Foz do Iguaçu. Não existe um estudo sobre a capacidade de suporte (K) do P.E. de Vila Velha, em Ponta Grossa; consequentemente os animais não podem ficar continuamente sendo lá "despejados", o que pode estar provocando superexplosão local de algumas populações.

Tabela 3 - Animais vertebrados noticiados pela imprensa regional: Total de animais detectados e animais mortos

\begin{tabular}{|c|c|c|}
\hline $\begin{array}{c}\text { Classes de animais } \\
\text { noticiadas/ } \\
\text { Famílias } \\
\end{array}$ & $\begin{array}{l}\text { Espécies identificadas } \\
\text { Nome popular/ } \\
\text { nome cientifico }\end{array}$ & $\begin{array}{c}\text { Animais mortos/ } \\
\text { Total de animais detectados } \\
\text { pela amostragem }\end{array}$ \\
\hline $\begin{array}{l}\text { Mammalia } \\
\text { Canidae } \\
\text { Mustelidae } \\
\text { Felidae } \\
\text { Cervidae } \\
\text { Agoutidae } \\
\end{array}$ & $\begin{array}{l}\text { Guará / Chrysocyon brachyurus } \\
\text { Lontra / Lutra longicaudis } \\
\text { Onça-parda / Puma concolor } \\
\text { Jaguatirica / Leopardus pardalis } \\
\text { Gato-do-mato / Leopardus wiedii } \\
\text { Veado-pardo ?/ Mazama americana } \\
\text { Paca / Agouti paca }\end{array}$ & 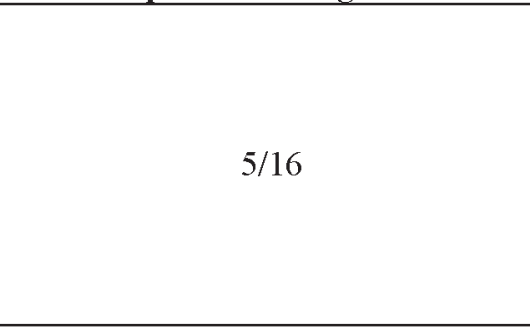 \\
\hline $\begin{array}{l}\text { Aves } \\
\text { Psittacidae } \\
\text { Hirundinidae } \\
\text { Turdidae } \\
\text { Cotingidae } \\
\text { Icteridae } \\
\text { Emberizidae } \\
\\
\text { Fringillidae } \\
\text { Corvidae } \\
\end{array}$ & $\begin{array}{l}\text { Tiriva / Pyrrhura frontalis } \\
\text { Andorinha / Hirundinidae } \\
\text { Sabiá / Turdus sp. } \\
\text { Araponga / Procnias nudicollis } \\
\text { Chupim / Gnorimopsar chopi } \\
\text { Canário-da-terra / Sicalis flaveola } \\
\text { Coleirinho / Sporophila caerulescens } \\
\text { Caboclinho / Sporophila sp. } \\
\text { Curió / Oryzoborus angolensis } \\
\text { Tico-tico-rei / Coryphospingus cucullatus } \\
\text { Azulão/ Passerina brissonii } \\
\text { Pintassilgo / Carduelis magellanicus } \\
\text { Gralha / Cyanocorax chrysops }\end{array}$ & $22 / 603$ \\
\hline $\begin{array}{l}\text { Reptilia } \\
\text { Teiidae } \\
\end{array}$ & $\begin{array}{l}\text { Lagarto-do-papo-amarelo / } \\
\text { Tupinambis sp. }\end{array}$ & $1 / 1$ \\
\hline $\begin{array}{l}\text { Pisces } \\
\text { Cyprinidae } \\
\text { Characidae } \\
\text { Erythrinidae } \\
\text { Pimelodidae } \\
\text { Loricariidae } \\
\text { Cichlidae }\end{array}$ & $\begin{array}{l}\text { Carpa / Cyprinus carpio } \\
\text { Lambari / Astyanax cf. eigenmaniorum } \\
\text { Lambari / Astyanax sp. } \\
\text { Traíra / Hoplias malabaricus } \\
\text { Bagre / Pimelodidae } \\
\text { Cascudo / Loricariidae } \\
\text { Cará / Geophagus brasiliensis } \\
\text { Tilápia / Tilapia sp. }\end{array}$ & centenas de peixes de várias espécies \\
\hline
\end{tabular}


Mesmo considerando o valor documental das notícias, outros agravos relacionados à fauna regional, infelizmente não tão raros, não vimos noticiados, como pode-se constatar no P.E. do Guartelá, o lobo-guará (Chrysocyon brachiurus), e no P.E. de Vila Velha, o quati (Nasua nasua), o jacu (Penelope obscura) e o lagarto (Teiidae) comendo restos de alimentos de turistas, e a imprensa pode contribuir na educação e conscientização ambiental da população, e das autoridades locais/regionais.

Múltiplos esforços e estratégias devem ser encetados visando atingir as metas assumidas pela Agenda 21 (Ipardes, 2001; Sato; Santos, 1996). O monitoramento das alterações na estrutura da paisagem é de fundamental importância, e aí também a documentação pela imprensa - do que se constitui numa rede de impactos ambientais - pode ter papel significativo, para que pesquisas sejam desenvolvidas e medidas preventivas voltadas para a conservação possam ser sugeridas. Um trabalho específico sobre a percepção da fauna ornitológica no ensino fundamental revelou que diversas espécies -apontadas nas notícias- ocorrem em áreas urbanas da região e são conhecidas pelos alunos (Schmitt e Ayres, 2000), o que reforça as possibilidades do uso desse veículo.

A amostragem tendo as notícias como indicadoras de impactos pode constituir consistente arcabouço de dados para subsidiar programas de ensino, assim como, propostas em Educação e Planejamento Ambiental; contribuindo na adoção de estratégias para a conservação da diversidade faunística na região, também como útil documento de apoio no âmbito do direito ambiental. Acreditamos ainda, que tais aplicações poderão contribuir reciprocamente no campo do jornalismo científico, com melhor adequação e tratamento nas informações (notícias) passíveis de outras análises, e nas interfaces pesquisa/ensino/mídias.

Agradecimentos

Aos Profs. Drs. Nivaldo Nordi, Haydée Torres de Oliveira (PPG-ERN UFScar) e Carlos Eduardo Matheus (CRHEA-USP) pela valiosa contribuição.

\section{REFERÊNCIAS}

1. AYRES, O.M. Conhecimento etnoecológico dos guartelianos do Vale do Rio Iapó e os saberes sobre a fauna dos Campos
Gerais. Subsídios a Educação e ao Planejamento Ambiental na APA da Escarpa Devoniana (Estado do Paraná). Programa de Pós-Graduação em Ecologia e Recursos Naturais, São Carlos, SP, UFSCar, 2002.

2. BARTHES, R. A mensagem fotográfica. In: Teoria da cultura de massa. Paz e Terra, Rio de Janeiro, 1978.

3. BENNEMANN, S.T.; SHIBATA, O.A.; GARAVELLO, J.C. Peixes do Rio Tibagi: uma abordagem ecológica. Ed. UEL, Londrina, PR, 2000, 62p.

4. BORGES, C.R.S. Composição mastofaunística do Parque Estadual de Vila Velha, Ponta Grossa, Paraná, Brasil. Curitiba, PR, UFPR, 1989, 358 p.

5. BRASIL, Ministério da Educação, Secretaria de Educação Média e Tecnológica. Parâmetros curriculares nacionais: ensino médio. Brasília, DF, 1999, 364 p.

6. , Webmaster IBAMA. http://www.ibama.gov.br/

7. CARVALHO, C.T. Lista nominal dos mamíferos brasileiros. Bol. Técn. IF. 37:31-115, 1983.

8. CONFERÊNCIA DAS NAÇÕES UNIDAS SOBRE MEIO AMBIENTE E DESENVOLVIMENTO (1992: Rio de Janeiro). Agenda 21. Curitiba, IPARDES, 2001, 260p.

9. GILMORE, R. M. Fauna e etnozoologia da América do Sul tropical. In: RIBEIRO, D. (ed.) et alii. Suma Etnológica Brasileira 1 -Etnobiologia. Vozes, Petrópolis, RJ, 1986, p. 189-233.

10. JOHN, L. A imprensa "especializada": Um papel ainda incerto na educação ambiental. In: TrAJBER, R.; MANZOCHI, L.H. (Org.) Avaliando a educação ambiental no Brasil: Materiais Impressos. Gaia, São Paulo, 1996, p.153-172.

11. MARGARIDO, C.C.T. Mamíferos ameaçados de extinção no Paraná. In: Lista vermelha de animais ameaçados de extinção no Estado do Paraná. Curitiba, SEMA/GTZ, 1995, p.545,165 .

12. Mendes, J.C. Paleontologia Geral. São Paulo T. A Queiroz, Editor/ Edusp, 1988, 347p.

13. OLIVEIRA, M. Hemeroteca escolar: uma usina de cidadania. In: Programa de Educação Ambiental do Vale do Ribeira. São Paulo: SEMA/SEED, 1992. [226p.], p. 261-278.

14. OLIVEIRA, T.G. Neotropical cats. São Luís, EDUFMA, 1994, 220 p.

15. SATO, M. Educação Ambiental. São Carlos, PPG-ERN/ UFSCar, 1995, 52p.

16. _ _ ; SANTOS, J.E. Agenda 21 em sinopse. São Carlos, PPG-ERN/UFSCar, 1996, 41p.

17. SEVERI, W.; CORDEIRO, A.A.M. Catálogo de peixes da bacia do Rio Iguaçu. Curitiba, GTZ, 1994, 118p.

18. SCHERER-NETO, P.; STRAUBE, F.C. Aves do Paraná: história, lista anotada e bibliografia. Ed. dos autores, Curitiba, 1995, 79p. 
19. SCHMITT, J. eAYRES, O.M. Percepção ambiental da fauna ornitológica urbana de Ponta Grossa (PR) por alunos do ensino fundamental de escola pública. Anais do III Encontro Paranaense de Educação Ambiental, Ponta Grossa, PR, 2000, p. 37-45.

20. SEVERINO,A.J. Metodologia do trabalho científico. Cortez, São Paulo, 1996, 272p.

21. Cortez, 1995, 72p.
22. SICK, H. Ornitologia brasileira. Nova Fronteira, Rio de Janeiro, 1997, 912p.

23. SILVA, F. Mamíferos silvestres do Rio Grande do Sul. Porto Alegre, Fundação Zoobotânica do Rio Grande do Sul, 1984, 244p.

24. STRAUBE, F.C. Aves ameaçadas de extinção no Paraná. In: Lista vermelha de animais ameaçados de extinção no Estado do Paraná. SEMA/GTZ, Curitiba, 1995, p. 50-127, 166-168 
Apêndice - Os Animais dos Campos Gerais (Pr): Impactos Ambientais Noticiados pela Imprensa Regional

\begin{tabular}{|c|c|c|c|}
\hline n. ${ }^{\circ}$ & Título & Fonte/Data & Observações \\
\hline 1 & $\begin{array}{l}\text { "Caçada" a puma mobiliza } \\
\text { soldados do CB } \\
\text { Bombeiros retiram puma de } \\
\text { porão na Vila Velha }\end{array}$ & \begin{tabular}{|l} 
Jornal da Manhã \\
22/08/1997
\end{tabular} & $\begin{array}{l}\text { Manchete com foto } \mathrm{p} \& \mathrm{~b} \text {, detalhe de onça-parda, } \\
\text { amarrada com cordas e sendo transportada. } \\
\text { Página 4C, notícia e foto. }\end{array}$ \\
\hline 2 & $\begin{array}{l}\text { Puma } \\
\text { Leão selvagem surge no Jardim } \\
\text { Carvalho }\end{array}$ & $\begin{array}{l}\text { Diário da Manhã } \\
\text { 22/08/1997 }\end{array}$ & $\begin{array}{l}\text { Manchete, com foto p\&b detalhe de onça-parda, } \\
\text { amarrada com cordas e sendo transportada; plano } \\
\text { mais aberto que no outro jornal. } \\
\text { Segurança: Página } 22 \text {. }\end{array}$ \\
\hline 3 & $\begin{array}{l}\text { Onça invade residência em } \\
\text { Ponta Grossa } \\
\text { Onça é capturada após invadir } \\
\text { uma casa. }\end{array}$ & $\begin{array}{l}\text { O Estado do } \\
\text { Paraná } \\
\text { 22/08/1997 }\end{array}$ & $\begin{array}{l}\text { Chamada, com nota } 1^{\text {a }} \text { página } \\
\text { Página 15.Uma onça foi capturada em residência } \\
\text { na Vila Velha, proximo ao centro de Ponta Grossa. }\end{array}$ \\
\hline 4 & $\begin{array}{l}\text { Rio Pitangui sofre com poluição } \\
\text { e centenas de peixes são mortos. } \\
\text { Centenas de peixes aparecem } \\
\text { mortos no Rio Pitangui. }\end{array}$ & $\begin{array}{l}\text { Diário da Manhã } \\
\text { 24/10/1997 }\end{array}$ & $\begin{array}{l}\text { Manchete, com foto } \mathrm{p} \& \mathrm{~b} \\
\text { Página 5. Legenda: "Os peixes começaram a } \\
\text { aparecer mortos na tarde de quarta-feira na } \\
\text { localidade de Bocaina". }\end{array}$ \\
\hline 5 & $\begin{array}{l}\text { Setembrino relaxa flagrante do } \\
\text { lagarto } \\
\text { Lagarto }\end{array}$ & $\begin{array}{l}\text { Diário da Manhã } \\
\text { 26/10/1997 }\end{array}$ & $\begin{array}{l}\text { Página } 30 \\
\text { Idem. Chamada com nota na 1.' página. }\end{array}$ \\
\hline 6 & $\begin{array}{l}\text { Campos Gerais apres entam } \\
\text { maior indice do PR de infrações } \\
\text { contra meio ambiente } \\
\end{array}$ & $\begin{array}{l}\text { Diário da Manhã } \\
\text { 25/04/1998 }\end{array}$ & $\begin{array}{l}\text { Segurança. Página 26. Policia Florestal notifica } \\
\text { inúmeras infrações contra fauna e flora na região } \\
\text { dos Campos Gerais. }\end{array}$ \\
\hline 7 & $\begin{array}{l}\text { Policiais florestais agem: } \\
\text { Material de pesca e caça } \\
\text { apreendido foi considerado } \\
\text { expressivo } \\
\text { Policia Florestal apreende } \\
\text { materiais de caça e pesca } \\
\end{array}$ & \begin{tabular}{|l} 
Página Um \\
30/10/1998
\end{tabular} & $\begin{array}{l}\text { Manchete com foto p\&b } \\
\text { Página 8. Policiais florestais recolheram após uma } \\
\text { ação conjunta material sendo usado para caça e } \\
\text { pesca ilegais. Legenda: Material apreendido pela } \\
\text { Policia Florestal é encaminhado à Div. Policial. }\end{array}$ \\
\hline 8 & $\begin{array}{l}\text { Acidente contamina rios em } \\
\text { Pirai } \\
\text { Herbicida polui } 20 \text { quilômetros } \\
\text { de rio }\end{array}$ & \begin{tabular}{|l} 
Jornal da Manhã \\
11/12/1998
\end{tabular} & $\begin{array}{l}\text { Manchete: O manuseio criminoso de um } \\
\text { pulverizador ocasionou a morte de diversas } \\
\text { espécies de peixes por mais de } 20 \text { quilômetros. } \\
\text { Notícia. Uma grande quantidade de peixes } \\
\text { apareceu morta nos rios Butiá e Piraí, em Piraí do } \\
\text { Sul, decorrente da possível aplicação do herbicida } \\
\text { Gramoxone em uma fazenda. }\end{array}$ \\
\hline 9 & $\begin{array}{l}\text { Aves apreendidas aqui serão } \\
\text { soltas em Curitiba }\end{array}$ & $\begin{array}{l}\text { Diário da Manhã } \\
\text { 06/02/1999 }\end{array}$ & $\begin{array}{l}\text { Página 9. Geral. Ibama e Policia Florestal } \\
\text { encaminharam para Curitiba, } 48 \text { pássaros silvestres } \\
\text { mantidos em cativeiro em Ponta Grossa. Legenda: } \\
\text { Pássaros silvestres passarão por dieta natural. } \\
\end{array}$ \\
\hline 10 & $\begin{array}{l}\text { Empresa transforma fósseis em } \\
\text { pedra brita no municipio } \\
\text { Técnicos salvam da moagem } 450 \\
\text { quilos de fósseis: Toneladas das } \\
\text { rochas com materiais } \\
\text { fossilizados da era Devoniana } \\
\text { viraram pedra brita para } \\
\text { calçamento }\end{array}$ & \begin{tabular}{|l} 
Jornal da Manhã \\
25/05/1999
\end{tabular} & $\begin{array}{l}\text { Página 1B Cotidiano: Chamada 1. página, com } \\
\text { foto p\&b. } \\
\text { Página 3B; Cotidiano: com foto de fósseis em } \\
\text { rocha. Legenda: "Situação interna da Estação, } \\
\text { onde técnicos do município cogitam em instalar } \\
\text { bibliotecas e outros pontos culturais." } \\
\text { Legenda: Rochas salvas da compactação estão } \\
\text { guardadas para o estudo em laboratórios e } \\
\text { posterior envio a museus. }\end{array}$ \\
\hline
\end{tabular}




\begin{tabular}{|c|c|c|c|}
\hline 11 & $\begin{array}{l}\text { Florestal apreende } 1.100 \mathrm{~m} \text { de } \\
\text { rede }\end{array}$ & $\begin{array}{l}\text { Jornal da Manhã } \\
\text { 23/07/1999 }\end{array}$ & $\begin{array}{l}\text { Página B1. Notícia com } 2 \text { fotos. Legendas: "A } \\
\text { Policia Florestal apreendeu mais de } 1000 \mathrm{~m} \text { de } \\
\text { rede em operações realizadas na região." } \\
\text { "O sargento Spinassi, do Batalhão de Policia } \\
\text { Florestal: crimes ambientais devem ser } \\
\text { denunciados." }\end{array}$ \\
\hline 12 & $\begin{array}{l}\text { Moradores encontram animal } \\
\text { silvestre }\end{array}$ & $\begin{array}{l}\text { Página Um } \\
24 \text { a } 03 / 08 / 1999\end{array}$ & $\begin{array}{l}\text { Manchete } 1^{a} \text { página, com foto de filhote. } \\
\text { Legenda: "Patrícia Fadel [veterinária] em análise } \\
\text { do filhote de gato do mato." }\end{array}$ \\
\hline 13 & $\begin{array}{l}\text { Arrastão da Florestal abrange a } \\
\text { região }\end{array}$ & $\begin{array}{l}\text { Diário da Manhã } \\
\text { 04/09/1999 }\end{array}$ & $\begin{array}{l}\text { Notícia. Policiais florestais fizeram apreensões em } \\
\text { toda região dos Campos Gerais. }\end{array}$ \\
\hline 14 & $\begin{array}{l}\text { Ibama apreende animais } \\
\text { mantidos em cativeiro } \\
\text { Animais apreendidos são soltos } \\
\text { em Vila Velha }\end{array}$ & $\begin{array}{l}\text { Diário dos } \\
\text { Campos } \\
29 / 09 / 1999\end{array}$ & $\begin{array}{l}\text { Manchete } 1^{\text {a }} \text { página, com foto colorida. Legenda: } \\
\text { "Policial mostra pele de jaguatirica encontrada em } \\
\text { cativeiro" (duplica a imagem). Notícia com foto de } \\
\text { paca. Legenda: "Através de denuncia anônima, } \\
\text { policiais chegaram aos animais." }\end{array}$ \\
\hline 15 & $\begin{array}{l}\text { Florestal prende caçador em } \\
\text { flagrante } \\
\text { Caçador é preso em flagrante em } \\
\text { Santa Cruz }\end{array}$ & $\begin{array}{l}\text { Jornal da Manhã } \\
\text { 29/09/1999 }\end{array}$ & $\begin{array}{l}\text { Manchete } 1^{\text {a }} \text { página, com foto. Legenda: "Pacas, } \\
\text { armas, pássaros e materiais de pesca predatória } \\
\text { foram apreendidos pela Policia Florestal e Ibama". } \\
\text { Página 1B, matéria com } 2 \text { fotos. Legenda: "Paca } \\
\text { apreendida pela Policia Florestal foi solta no } \\
\text { Parque de Vila Velha." "Pele de jaguatirica foi } \\
\text { apresentada por soldados da Florestal em casa de } \\
\text { caçador." }\end{array}$ \\
\hline 16 & ende caçador de & $\begin{array}{l}\text { Jornal da Manhã } \\
\text { 05/10/1999. }\end{array}$ & $\begin{array}{l}\text { Com foto. Legenda: "Equipe da Policia Florestal } \\
\text { de Vila Velha que apreendeu pássaros, gaiolas e } \\
\text { até entorpecentes durante as ultimas operações." }\end{array}$ \\
\hline 17 & $\begin{array}{l}\text { Lobo é encontrado na Vila Ana } \\
\text { Rita } \\
\text { Policia Florestal captura lobo na } \\
\text { Vila Ana Rita }\end{array}$ & $\begin{array}{l}\text { Jornal da Manhã } \\
\text { 22/10/1999 }\end{array}$ & $\begin{array}{l}\text { Manchete } 1^{\text {a }} \text { página, com foto colorida do animal. } \\
\text { Legenda: "O lobo foi solo na manhã de ontem na } \\
\text { região do Parque Estadual de Vila Velha." } \\
\text { Página A7, Geral; Foto p\&b. } \\
\text { Legenda: "O lobo foi solto na manhã de ontem na } \\
\text { região do Parque Estadual de Vila Velha." }\end{array}$ \\
\hline 18 & $\begin{array}{l}\text { Lobo é capturado na Vila Ana } \\
\text { Rita } \\
\text { Policia Florestal apanha lobo- } \\
\text { guará }\end{array}$ & $\begin{array}{l}\text { Diário da Manhã } \\
\text { 22/10/1999 }\end{array}$ & $\begin{array}{l}\text { Manchete } 1^{\text {a }} \text { página, com foto colorida do animal } \\
\text { sendo libertado. Legenda: "Lobo-guará é libertado } \\
\text { por policiais florestais no Parque Estadual de Vila } \\
\text { Velha." } \\
\text { Página } 18 \text {, Segurança, com foto p\&b. } \\
\text { Legenda: "O lobo-guará é libertado no Parque de } \\
\text { Vila Velha." }\end{array}$ \\
\hline 19 & $\begin{array}{l}\text { Piracema: Iniciam hoje } \\
\text { proibiçôes de pesca }\end{array}$ & $\begin{array}{l}\text { Diário da Manhã } \\
\text { 05/11/1999. }\end{array}$ & $\begin{array}{l}\text { Manchete } 1^{a} \text { página, com foto. Legenda: "O } \\
\text { Instituto Ambiental e Recursos Hídricos alerta que } \\
\text { a partir de hoje a atividade pesqueira fica proibida, } \\
\text { em função do inicio da piracema, até o dia } 2 \text { de } \\
\text { fevereiro". } \\
\text { Página } 18 \text {, Segurança, com } 2 \text { fotos . Legenda: "O } \\
\text { pescador não pode pegar mais do que cinco kg." } \\
\text { "Spinassi: a Florestal vai intensificar as patrulhas". }\end{array}$ \\
\hline 20 & $\begin{array}{l}\text { Ibama apreende cem pássaros } \\
\text { silvestres } \\
\text { Ibama apreende canarinhos } \\
\text { terra }\end{array}$ & $\begin{array}{l}\text { Diário da Manhã } \\
\text { 19/02/2000 }\end{array}$ & $\begin{array}{l}\text { Manchete } 1^{a} \text { página, com foto. } \\
\text { Página } 16 \text {, Segurança, com foto. Legenda: "A } \\
\text { operação realizada em Ipiranga resultou na } \\
\text { apreensão de } 96 \text { canários belga, além de outros } \\
\text { exemplares". }\end{array}$ \\
\hline
\end{tabular}




\begin{tabular}{|c|c|c|c|}
\hline 21 & $\begin{array}{l}\text { Apreensão confirma tráfico de } \\
\text { aves } \\
\text { Apreensão de } 100 \text { aves confirma } \\
\text { rota }\end{array}$ & $\begin{array}{l}\text { Diário dos } \\
\text { Campos } \\
\text { 19/02/2000. }\end{array}$ & $\begin{array}{l}\text { Manchete } 1^{a} \text { página, com foto colorida. Legenda: } \\
\text { "Segundo a policia, Ponta Grossa chega a registrar } \\
\text { no mercado ilegal mil pássaros vendidos por } \\
\text { semana [anos] vendidos e transportados } \\
\text { irregularmente para São Paulo." } \\
\text { Página } 10 \AA \text {, Policia, com foto. } \\
\text { Legenda: "Pássaros mortos foram retirados das } \\
\text { gaiolas e viveiros pelos policiais do Ibama". }\end{array}$ \\
\hline 22 & $\begin{array}{l}\text { Aves reconquistam a liberdade } \\
\text { Aves silvestres são devolvidas à } \\
\text { natureza }\end{array}$ & \begin{tabular}{|l|} 
Diário dos \\
Campos \\
20 e $21 / 02 / 2000$
\end{tabular} & $\begin{array}{l}\text { Manchete } 1^{a} \text { página, com foto. Legenda: "A } \\
\text { Policia Florestal e o Ibama soltaram ontem os } \\
\text { pássaros na região do Parque Estadual de Vila } \\
\text { Velha". } \\
\text { Página 8A, com foto. Legenda: "Pássaros sob o } \\
\text { trauma do cativeiro foram soltos em área segura } \\
\text { em Vila Velha." }\end{array}$ \\
\hline 23 & $\begin{array}{l}\text { Ibama faz campanha contra } \\
\text { tráfico de pássaros }\end{array}$ & Jornal da Manhã & $\begin{array}{l}\text { Manchete } 1^{a} \text { página, com foto. Legenda: "Policiais } \\
\text { florestais, soltam pássaros apreendidos na casa de } \\
\text { traficante de aves silvestres." } \\
\text { Página B1, com foto. Legenda: "Policiais } \\
\text { Florestais transportam gaiolas e pássaros } \\
\text { apreendidos em casa de traficante". }\end{array}$ \\
\hline 24 & $\begin{array}{l}\text { Florestal realiza Operação } \\
\text { Bloqueio: Material de pesca foi } \\
\text { apreendido nos rios Imbituvão e } \\
\text { Tibagi em arrastão da Policia } \\
\text { Florestal }\end{array}$ & \begin{tabular}{|l} 
Diário dos \\
Campos \\
25/02/2000.
\end{tabular} & $\begin{array}{l}\text { Página } 10 \AA \text {, Segurança, com foto. } \\
\text { Legenda: "Operação foi simultânea em todo o } \\
\text { Estado. Em Curitiba, houve exposição de materiais } \\
\text { apreendidos". }\end{array}$ \\
\hline 25 & $\begin{array}{l}\text { Espécies na lista de extinção são } \\
\text { preservadas no Guartelá. }\end{array}$ & \begin{tabular}{|l} 
Diário dos \\
Campos \\
05 a 08/03/2000
\end{tabular} & $\begin{array}{l}\text { Página 10A, Cidades: Entrevistas com moradores } \\
\text { tradicionais do Guartelá, e com o pesquisador O. } \\
\text { M. Ayres. } \\
\text { Poluição industrial no Rio Iapó. }\end{array}$ \\
\hline 26 & $\begin{array}{l}\text { Peixes morrem às centenas em } \\
\text { Furna }\end{array}$ & \begin{tabular}{|l} 
Jornal da Manhã \\
16/03/2000
\end{tabular} & $\begin{array}{l}\text { Manchete } 1^{\text {a }} \text { página, com foto colorida- Furnas/ } \\
\text { Ponta Grossa. Legenda: "Mirante e teleférico da } \\
\text { Furna n }{ }^{\circ} 1 \text {, dentro do Parque Estadual de Vila } \\
\text { Velha: peixes estão morrendo as centenas." }\end{array}$ \\
\hline 27 & $\begin{array}{l}\text { Laudo confirma causa de morte } \\
\text { de peixes }\end{array}$ & $\begin{array}{l}\text { Jornal da Manhã } \\
\text { 05/04/2000 }\end{array}$ & $\begin{array}{l}\text { Página } 4 \text { A, foto p\&b peixes mortos e 'mais } \\
\text { alguma coisa', } \\
\text { Legenda: "Peixes e uma andorinha mortos, bóiam } \\
\text { na água da Furna número 1: sufocação } \\
\text { comprovada". Caixote: "Furna pode abrigar } \\
\text { espécie exclusiva". Entrevista com o pesquisador } \\
\text { R. Artoni. }\end{array}$ \\
\hline 28 & $\begin{array}{l}\text { AAL terá que pagar multa de } R \$ \\
452 \text { mil por danos ambientais } \\
\text { AAL será multada em } R \$ 452 \text { mil }\end{array}$ & $\begin{array}{l}\text { Diário da Manhã } \\
\text { 12/04/2000 }\end{array}$ & $\begin{array}{l}\text { Manchete } 1 \text { página, com foto color peixes } \\
\text { boiando, e a legenda "O IAP instruiu para } \\
\text { população a não consumir os peixes mortos em } \\
\text { função do vazamento de álcool" } \\
\text { Idem página 10, foto p\&b, com legenda "No } \\
\text { acidente ocorrido em Piraí do Sul, cerca de } 100 \text { mil } \\
\text { litros de álcool foram despejados em arroio". } \\
\end{array}$ \\
\hline 29 & $\begin{array}{l}\text { Crianças encontram filhote de } \\
\text { lontra } \\
\text { Crianças acham lontra às } \\
\text { margens do Rio Verde }\end{array}$ & $\begin{array}{l}\text { Diário da Manhã } \\
16 / 06 / 2000\end{array}$ & $\begin{array}{l}\text { Manchete } 1^{\text {a }} \text { página, com foto colorida do animal } \\
\text { na mão de menino. Legenda: "As crianças do } \\
\text { Jardim dos Tropeiros encontram o fillhote de } \\
\text { lontra." } \\
\text { Página 10, Geral, com foto. Legenda: "O filhote } \\
\text { da lontra vai ser levado ao passeio público de } \\
\text { Curitiba". }\end{array}$ \\
\hline
\end{tabular}




\begin{tabular}{|c|c|c|c|}
\hline 30 & Ibama fecha rinha da $N$. Rússia & $\begin{array}{l}\text { Diário da Manhã } \\
\text { 13/09/2000 }\end{array}$ & $\begin{array}{l}\text { Manchete, } 1^{\text {a }} \text { página com foto colorida. Legenda: } \\
\text { "Na rinha fechada ontem na Nova Rússia, o Ibama } \\
\text { encontrou materiais de divulgação, regulamentos } \\
\text { e o ambiente preparado para brigas de galo. } \\
\text { Noticia com foto p\&b. Legenda: "O chefe regional } \\
\text { do Ibama, João Antônio, técnicos do instituto e } \\
\text { peritos da Policia Civil interditaram ontem o } \\
\text { prédio onde funcionava a rinha. Antônio, do Ibama } \\
\text { mostra cartazes contendo regulamento da rinha". }\end{array}$ \\
\hline 31 & $\begin{array}{l}\text { Ibama descobre rinha no Sabará } \\
\text { e multa criador de galos de briga }\end{array}$ & $\begin{array}{l}\text { Diário da Manhã } \\
14 / 09 / 2000\end{array}$ & $\begin{array}{l}\text { Página } 18 . \text { Em menos de } 24 \text { horas, o Ibama, fechou } \\
\text { a segunda rinha de galos, esta no Sabará. }\end{array}$ \\
\hline 32 & $\begin{array}{l}\text { Policia Florestal apreende } \\
\text { pássaros e armas na região }\end{array}$ & $\begin{array}{l}\text { Diário da Manhã } \\
11 / 10 / 2000\end{array}$ & $\begin{array}{l}\text { Manchete } 1^{a} \text { página ( } 41 \text { "espécies" [espécimes]: } \\
\text { canários-da-terra, pintassilgos, sabiás); também } \\
\text { "uma pele e patas de veado". }\end{array}$ \\
\hline 33 & $\begin{array}{l}\text { Policia Florestal intensifica } \\
\text { operações e faz apreensões }\end{array}$ & $\begin{array}{l}\text { Diário da Manhã } \\
26 / 10 / 2000\end{array}$ & Página 18 , sem foto. \\
\hline 34 & $\begin{array}{l}\text { Homem é detido com aves } \\
\text { silvestres } \\
\text { Homem preso com } 370 \text { aves } \\
\text { silvestres }\end{array}$ & $\begin{array}{l}\text { Diário dos } \\
\text { Campos } \\
24 / 11 / 2001\end{array}$ & $\begin{array}{l}\text { O Grupo de Operações Especiais da Policia Militar } \\
\text { deteve Adolar Plotecia, } 68 \text { com } 370 \text { pássaros } \\
\text { silvestres. } \\
\text { Página 9. Detido pelo Grupo de Operações } \\
\text { Especiais (GOE), Adolar Plotecia, 68, com } 370 \\
\text { pássaros silvestres, os quais foram soltos no } \\
\text { Parque Estadual de Vila Velha. }\end{array}$ \\
\hline
\end{tabular}

